\title{
Tumor Identifier Domain
}

National Cancer Institute

\section{Source}

National Cancer Institute. Tumor Identifier Domain. NCI Thesaurus. Code C106577.

A domain that represents the data that uniquely identifies tumors. 